index comunicación | no 9 (2) 2019 | Páginas 101-134

E-ISSN: 2174-1859 | ISSN: 2444-3239 | Depósito Legal: M-19965-2015

Recibido el 29_04_2019 | Aceptado el 12_06_2019 | Publicado el 01_07_2019

\title{
LA FIGURA DEL NARRADOR EN LA FICCIÓN RADIOFÓNICA SERIADA: EL CASO DE 'TAXI KEY'
}

THE ROLE OF NARRATOR IN SERIAL RADIO FICTION: THE CASE OF 'TAXI KEY'

\section{Elisa Arias-García \\ eariasga@upsa.es ID https://orcid.org/0000-0001-6208-3460 \\ Universidad Pontificia de Salamanca}

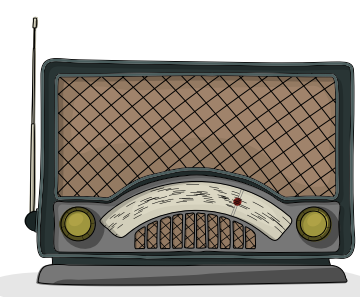

Para citar este trabajo: Arias-García, E. (2019). La figura del narrador en la ficción radiofónica seriada: el caso de Taxi Key. index.comunicación, 9(2), 101-134. 
Resumen: A pesar del protagonismo que adquieren los diálogos de los personajes en la creación de una serie, no podemos obviar que la palabra radiofónica puede hallarse representada a su vez por la presencia del narrador. Por ello, en el presente artículo se ha seleccionado como objeto de estudio la emblemática serie policiaca Taxi Key, para poder determinar el porcentaje de aparición de la figura del narrador en los episodios de la serie, la tipología de narrador que prevalece y las principales funciones que desempeña en este producto ficcional. Se trata de un estudio exploratorio en el que se han realizado análisis descriptivos e inferenciales a partir de los guiones radiofónicos originales de Taxi Key. Los resultados del estudio revelan que la presencia de la figura del narrador alcanza la mayoría significativa en los capítulos de la muestra, siendo el narrador autodiegético el que se erige como tipo de narrador más frecuente. Proporcionar información contextual, actuar de nexo y transición entre escenas y caracterizar a los personajes o incorporarlos a escena son las funciones del narrador que prevalecen en este seriado que permaneció casi veinte años en la antena de Radio Barcelona. Palabras clave: serie; Taxi Key; guion radiofónico; policiaco; narrador; autodiegético.

Abstract: In spite of the prominence acquired by dialogues among characters in creating a series, we cannot ignore that radio speech can be represented in turn by the narrators's presence. For this reason, in the present article the emblematic Taxi Key detective series has been selected as an object of study, in order to determine the narrators's appearance percentage in the series episodes, the narrator's typology that prevails and the main functions that plays in this fictional product. It is an exploratory study in which descriptive and inferential analyzes have been made from Taxi Key original radio scripts. The results of the study reveal that narrator's presence reaches the most significant prevalence in the episodes of the sample, being the autodiegetic narrator who stands as the most frequent type of narrator. Providing contextual information, acting as a nexus and transition device between scenes and assessing the characters or incorporating them on stage are the narrator's functions that prevail in this series that remained almost twenty years on Radio Barcelona network. Keywords: Series; Taxi Key; Radio Script; Detective Fiction Genre; Storyteller; Autodiegetic. 


\section{Introducción. La presencia del narrador en la ficción sonora seriada}

$\mathrm{Si}$ observamos el guion de una serie radiofónica podremos detectar que, por lo general, es la palabra el elemento del lenguaje radiofónico que adquiere una mayor presencia en cada capítulo. Ésta se halla representada fundamentalmente por los diálogos de los personajes, esencia expresiva de la radio (Arnheim, 1980); pues, como apunta Barea (1994), este tipo de género es en sí relato dramatizado. Y es que no cabe duda de que los personajes son una de las piezas clave en la creación de una serie; si bien, ello no impide que el guionista pueda recurrir a su vez a otras estrategias que contribuyan a diversificar los modos en que se manifiesta la palabra radiofónica. De esta forma, podemos hacer referencia a la posible presencia de un narrador.

Así, en la producción de un seriado será preciso decidir si la historia será guiada a través de la visión de un narrador, recurriendo de este modo a «un observador privilegiado de la realidad radiofónica que nos simplifica la composición del relato o el tránsito de una dimensión espacial / temporal a otra» (Balsebre, 2007: 190), o bien si se opta por la ausencia del mismo. En este sentido, Balsebre incide en que «el uso excesivo de la figura del narrador en la ficción dramática seriada $[. .$.$] ha devaluado$ significativamente su función narrativa». Del mismo modo, autores como Ortiz Sobrino y Volpini (2017: 19) apuntan lo siguiente:

En nuestra opinión, un dramático radiofónico, cualquier forma de audiodrama, debe, en la medida de lo posible, dar a la audiencia, al público, la sensación de que asiste a los hechos que se refieren. Se debería procurar, en consecuencia y en la medida de lo posible, prescindir del narrador. Quitar ese intermediario en un papel que sólo al receptor le corresponde: ver, percibir los paisajes y las formas, protagonizar la acción, estar allí.

Por su parte, Aguilera y Arquero (2017) manifiestan no ser partidarias del empleo de narradores, al igual que otros autores y creadores de ficción sonora. No obstante, resulta habitual seguir encontrando seriados de gran interés que hacen uso del narrador y eso no resta calidad a dichos espacios, ni entorpece su escucha. Entre ellos podemos citar algunos ejemplos como el reciente El Gran Apagón (en Podium Podcast) o el mítico Cuando Juan y Tula fueron a Siritinga, de RNE, serial en que se 
recurre a diversas fórmulas de narrador ${ }^{1}$, las cuales se alejan del tradicional modelo de narrador que aparecía en seriales como Ama Rosa (1959).

Balsebre (2007: 190) justifica la presencia de esta figura de la enunciación cuando el narrador proporciona información contextual de los antecedentes de la historia o de sus protagonistas; o una descripción visual de determinados ambientes o de los rasgos físicos de los personajes; o bien cuando la complejidad de la transición temporal de la continuidad dramática a partir de los elementos internos de la propia historia genera ambigüedad o confusión narrativa; o cuando la voz del narrador incorpora o identifica un personaje de la propia historia.

En este sentido, las principales funciones que un narrador suele desempeñar en los episodios de las series radiofónicas son las habituales de un narrador en un relato radiofónico de ficción. Estas son (Barea, 2000; Maza y Cervantes, 2000; Balsebre, 2007; Rodero y Soengas, 2010): proporciona información sobre la acción (pone en antecedentes a los oyentes de los sucesos que se relatarán en el capítulo, presenta, ubica o describe la acción dramática, que puede llegar a comentar en función de la tipología de narrador); aporta información contextual de carácter espacio-temporal (sobre el escenario en el que se encuentran ubicados los personajes, proporciona información visual de las localizaciones del capítulo, sitúa a los personajes en el espacio y el tiempo de la historia); organiza el relato, favorece la transición entre escenas, hace avanzar la trama, describe a los personajes (puede aportar un retrato visual de algunos de los rasgos que caracterizan a los personajes); e identifica a los personajes (haciendo alusión a datos como su nombre...) y los incorpora a escena.

En este contexto es preciso tener en cuenta a su vez que el rasgo distintivo que caracteriza los géneros de ficción seriados y los diferencia del resto de fórmulas ficcionales es la emisión en episodios. Dentro de la ficción radiofónica seriada

\footnotetext{
${ }^{1}$ Hurtado (2008), en su publicación Montando Siritinga, hace referencia a los distintos tipos de narrador que aparecen en el serial Cuando Juan y Tula fueron a Siritinga: «Varios tipos de narradores que cumplen todos los modelos de la clasificación de Rodero Antón (2005: 183-184). Estos son el clásico dios omnisciente editorial aquí convertido en dios de los seriales, interpretado por Roberto Cruz, uno de los grandes actores de RNE; Vairaumati y Tusitala, pareja de narradores que constantemente se transforman en protagonistas con sus devaneos amorosos y que lo mismo pasan de la omnisciencia general a la selectiva, que son reprendidos por el Dios de los Seriales y que dejan su puesto a otros narradores multiselectivos, con lo que abren paso a los saltos constantes en la narración clásica del serial y la ruptura y desestructuración de ésta» (Hurtado, 2008).
} 
encontramos fundamentalmente dos tipos de géneros: el serial y la serie. En el caso del serial existe «un conflicto dilatado en el tiempo que se prolonga de capítulo a capítulo» (Guarinos, 2009: 239), por lo que se registra una «continuidad argumental y temporal que se establece entre la acción dramática del final de un episodio y la del principio del episodio siguiente» (Balsebre, 2002: 237). Esto provoca que pueda ser más frecuente la presencia de la figura del narrador al actuar, en muchos casos, como memoria del oyente al inicio de cada capítulo.

A diferencia del serial, en la serie - género en el que nos centraremos en este artículo- existe un argumento autoconclusivo que se plantea y resuelve en cada episodio, independientemente de que pueda aparecer a su vez alguna trama horizontal. Por tanto, en aquellas series en las que el narrador está presente, éste no cumple la función de actuar como nexo entre capítulos en los términos citados anteriormente. Del mismo modo, en función del género al que se adscriba cada serie (costumbrista/de situación, policiaca...) es más o menos frecuente el uso del narrador ${ }^{2}$.

Tomando como referencia las premisas anteriores, en el presente artículo no abogaremos ni por el uso ni por la ausencia del narrador en la ficción sonora seriada, sino que consideramos que debe ser el autor de cada producto ficcional el que decida si es necesario o conveniente recurrir o no a esta figura de la enunciación, según el perfil del seriado que se pretenda crear. Del mismo modo, tampoco el narrador tiene por qué ser identificado como elemento prioritario del relato, sino que puede ser concebido como una pieza más del engranaje narrativo de la historia.

Existen diversas categorizaciones en lo que al tipo de narrador se refiere. Así, podemos aludir a tipologías clásicas y de referencia como las propuestas por Friedman, Todorov o Genette. De hecho, Martínez-Costa (1998) recuerda que los relatos radiofónicos tampoco escapan a las tipologías de narrador aportadas por la teoría literaria. El grado de conocimiento que el narrador dispone de la historia, su función participativa en la misma, así como el tipo de mediación que realiza (García

\footnotetext{
${ }^{2}$ Se puede consultar a su vez la clasificación que aporta Guarinos (2009) sobre los géneros ficcionales dramatizados en la que establece una diferenciación entre los géneros de hearing, en los que se desarrolla una historia sin mediación del narrador, y los géneros de telling, en los que existe mediación del narrador.
} 
Jiménez, 1996) se encuentran entre los criterios que guían las diversas clasificaciones.

En nuestro caso, tomaremos como referencia la tipología de Gerard Genette (Figures III, 1972/1989). Resulta de especial interés para este artículo la diferenciación que Genette (1989: 299) establece entre dos tipos de narrador:

- El narrador heterodiegético: ausente de la historia que cuenta.

- El narrador homodiegético: presente como personaje en la historia que cuenta.

En relación con la ausencia del narrador en la historia (heterodiegético), el autor aclara que ésta es absoluta; sin embargo, subraya que «la presencia tiene grados». De este modo, «habrá que distinguir al menos dos variedades dentro del tipo homodiegético: una en que el narrador es el protagonista de su relato [...]; otra en que el narrador desempeña un papel secundario», actúa como observador o testigo (Genette, 1989: 299). En el caso de las series radiofónicas podríamos identificar este segundo tipo con un personaje secundario o un personaje que, a pesar de formar parte del elenco de personajes principales y no episódicos, no es el protagonista.

Afirma Genette (1989: 300) que «para la primera variedad (que representa en cierto modo el grado intenso del homodiegético) reservamos el término, inevitable, de autodigético». Así, en este estudio hablaremos de narrador autodiegético para referirnos al narrador interpretado por el protagonista de la historia — personaje principal de la serie y del capítulo-, mientras que designaremos como homodiegético al personaje de la historia que adopta el papel de narrador, pero no es el protagonista de la serie/capítulo (a pesar de que ambos pertenezcan a la modalidad homodiegética formulada por Genette) ${ }^{3}$. Se añaden a continuación algunas

${ }^{3}$ Genette (1989: 302), al referirse al narrador, establece una doble categorización, clasificando esta figura tanto «por su nivel narrativo» (extradiegético / intradiegético), como «por su relación con la historia» (heterodiegético / homodiegético). Las posibles combinaciones de las tipologías citadas dan lugar a cuatro posibles modelos: extradiegético-heterodiegético, extradiegético-homodiegético, intradiegético-heterodiegético, intradiegético-homodiegético. En el estudio que nos ocupa nos centraremos exclusivamente en el análisis a partir de la clasificación que hace referencia al papel del narrador en la historia (heterodiegético, homodiegético y autodiegético). 
características más de los tipos de narrador citados (García Jiménez, 1996: 115-117; García Landa, 1998; García Peinado, 1998; Martínez Costa, 1998; Rodero, 2005):

- Narrador heterodiegético: es el narrador que cuenta una historia, pero que no forma parte de la diégesis. Es una «VOZ» o instancia de la enunciación textual que se encuentra fuera de la historia, pero su grado de conocimiento de los acontecimientos y personajes es completo. Dotado de omnisciencia y de ubicuidad. Se mantiene en el anonimato. Por lo general, se expresa en tercera persona. Se sitúa en un momento posterior a la historia que cuenta y contempla a ésta como una totalidad acabada. Esto lo faculta para hacer retrospecciones y anticipaciones.

- Narrador autodiegético (homodiegético-autodiegético): es aquel que relata sus propias experiencias como personaje central de la historia. Por lo general habla en primera persona, aunque se dan casos en que no se cumple esta norma. Narrador y personaje son un mismo sujeto, escindido en dos roles: el «yo narrado» y el «yo narradon». Su aparición en el relato tiene lugar en un tiempo posterior a la historia que cuenta. La historia, su historia, está constituida por acontecimientos que él conoce por haberlos vivido. Se da así una inadecuación, más o menos acusada, entre el pasado de la historia y el presente del discurso del narrador, entre el tiempo del «yo narrado» y el tiempo del «yo narrante».

- Narrador homodiegético: es la instancia de enunciación que, como personaje que es, asume la función de contar la historia y de comunicar informaciones que ha obtenido gracias a su intervención en la diégesis. Se diferencia del narrador autodiegético en que, siendo personaje como él, no es el personaje central de la historia. Al participar de la diégesis, el conocimiento de aquello que cuenta es, pues, un conocimiento directo.

El tipo de narrador y el grado de protagonismo que se le otorgue a éste en la serie influirá en el ritmo y tono del relato.

Es muy amplio el abanico de opciones que nos encontramos en el momento actual para poder innovar y crear productos seriados idóneos, con o sin narrador. 
La necesidad de presencia o ausencia del narrador dependerá del tipo de producto ficcional, así como de la categoría y formato de narrador que elijamos/diseñemos.

\section{El objeto de estudio: la serie radiofónica 'Taxi Key'}

Para realizar el análisis de la figura del narrador en el marco de la ficción radiofónica seriada se ha seleccionado una serie policiaca de referencia, entre otras cuestiones, por su perfil narrativo, repercusión que alcanzó entre la audiencia y número de años que se mantuvo en antena. Hablamos de: ¿Es usted buen detective? Aventuras de Taxi Key. Creada por el guionista Luis G. de Blain, y con Armando Blanch en la dirección artística, Taxi Key comienza a emitirse el sábado 2 de octubre de 1948 a las $22.30 \mathrm{~h}$. en Radio Barcelona. Se mantiene en antena durante casi veinte años, hasta finales de la década de los sesenta (con alguna interrupción durante este periodo). Los horarios y días de emisión de este espacio de treinta minutos fluctuarán en los distintos periodos.

La serie Taxi Key era el eje de contenido que articulaba el programa-concurso ¿Es usted buen detective ${ }^{4}$ Cada semana, tras la presentación en directo que realizaban los locutores del programa — en la que se citaba el título del capítulo, el guionista, director artístico, los actores que interpretarían el episodio semanal y los patrocinadores, entre otros datos-, los oyentes tenían la oportunidad de escuchar alguna de las aventuras del sagaz Taxi Key (interpretado por Isidro Sola, aunque el primer Taxi Key fue Ricardo Palmerola).

Así, en cada capítulo se planteaba un enigma que giraba en torno a la comisión de un hecho delictivo que el abogado, taxista y detective/investigador privado norteamericano Taxi Key debía resolver, en muchas ocasiones en compañía de Norah (personaje interpretado por la actriz de radioteatro Encarna Sánchez), su novia y posteriormente esposa (en la primera etapa era Geraldine quien desempeñaba este papel) y el inconfundible Glossop (Antonio Crespo), amigo del matrimonio. Si bien

${ }^{4}$ Como muestra, se incluye el fragmento inicial correspondiente al guion del 24 de marzo de 1951:

—LOCUTOR: Grandes Almacenes El Siglo S.A. se complacen en presentar el programa «Es usted buen detective».

-LOCUTORA: Con las Aventuras de Taxi Key y el breve Noticiario Gaessa, de interés para los poseedores de Tarjetas Gaessa.

-SINTONÍA DE TAXI KEY

-LOCUTOR: ¿Es usted buen detective?... Lo sabrá escuchando las aventuras de Taxi Key. 
no sólo era el personaje central de la serie quien tenía que resolver el misterio, puesto que, a lo largo del capítulo, la audiencia debía estar atenta a la investigación, ya que, de forma previa a emitirse la resolución del caso, se interrumpía la trama del episodio a golpe de gong y se daba paso al interrogatorio dedicado a los oyentes, a los que se proponía actuar como detectives y averiguar la identidad del criminal a cambio de un premio ${ }^{5}$ (guiones de Taxi Key y Balsebre, 2002).

Posteriormente, se retomaba el desenlace del episodio para que el carismático Taxi Key aportara, a modo de monólogo, todas las claves que permitían resolver el enigma y solventar la principal incógnita: ¿quién había cometido el crimen? Aventuras de Taxi Key se convirtió sin duda en una de las series policiacas más exitosas y con mayor repercusión entre la audiencia barcelonesa.

\section{Objetivos}

Una vez delimitados los aspectos fundamentales relativos a la figura del narrador en la ficción radiofónica seriada, y presentada la serie objeto de estudio, Taxi Key, se citan a continuación los objetivos prioritarios del artículo. Estos son:

- Cuantificar y analizar el porcentaje de aparición de la figura del narrador en los episodios que conforman la muestra.

- Determinar y caracterizar la tipología de narrador que prevalece en la serie.

- Identificar las principales funciones que desempeña el narrador en la serie Taxi Key.

\section{Metodología}

El estudio que se incluye a continuación forma parte de una investigación más amplia dedicada al análisis de las características narrativas de la serie radiofónica

5 -GONG

_LOCUTORA: «¿Es usted buen detective?... El primer radioyente que telefonee al 21.65.91 dando la solución del enigma será obsequiado con dos localidades para un cine de Barcelona... Y escuchen mientras tanto el Noticiario Gaessa de la semana» (fragmento correspondiente al guion emitido el 24 de marzo de 1951. Episodio: Crimen en la biblioteca pública). 
Taxi Key. Se trata de un estudio exploratorio en el que se incluyen análisis descriptivos e inferenciales. Se han utilizado tanto técnicas cuantitativas como cualitativas con el objetivo de aportar una perspectiva más amplia y completa de las diversas dimensiones que se pretenden analizar (Casetti y Di Chio, 1999; Igartua, 2006; García y Berganza, 2005; Hernández Sampieri, Fernández Collado y Baptista Lucio, 2010).

La muestra de estudio la constituyen cuarenta guiones radiofónicos originales de la serie policiaca Taxi Key ${ }^{6}$. Entre las razones por las que esta serie policiaca se ha seleccionado como objeto de análisis se encuentran las siguientes: el número de años que la serie permaneció en antena, el amplio número de guiones que se conservan, la popularidad que esta serie radiofónica alcanzó entre su audiencia y el interés que presenta el seriado Taxi Key desde el punto de vista narrativo y dramático. En lo relativo al método de selección de la muestra, y debido a las características de nuestro estudio, nos decantamos por una muestra de carácter no probabilístico, puesto que se persigue inferir, con carácter exploratorio, tendencias de la muestra seleccionada. Como se ha detallado anteriormente, este estudio forma parte de una investigación más amplia, por tanto, el perfil de la muestra se adscribe a esta circunstancia.

Se han aplicado criterios de carácter narrativo y cronológico en la selección de los guiones. En la muestra se encuentran representados todos los años de emisión de la serie, excepto aquellos en los que se interrumpe la difusión de Taxi Key (19591961). Se han definido tres épocas de estudio: época I, 1948-1950, años iniciales de la serie (30 por ciento de la muestra); época II, 1951 a 1958 (40 por ciento de la muestra); época III, desde 1962 hasta la finalización de la serie, en 1967 (30 por ciento de la muestra). Con esta distribución se puede afirmar que las tres épocas están homogéneamente representadas con $\mathrm{p}>, 05\left(\mathrm{Chi}^{2}=0,800 ; 2 \mathrm{gl} ; \mathrm{p}=, 670\right)$.

Por otra parte, es preciso puntualizar que se diseñó un instrumento de análisis que permitiera registrar la información cuantitativa y cualitativa de la investigación.

Para ello, se integraron en una misma herramienta elementos de análisis de carácter cuantitativo y cualitativo, para que de ese modo el procedimiento de recogida y análisis de datos correspondientes a cada guion se pudiera efectuar de

${ }^{6}$ Fuentes: Biblioteca de Comunicación y Hemeroteca General de la Universidad Autónoma de Barcelona, Radio Barcelona y Librería Negra y Criminal. 
forma simultánea y conjunta. El análisis estadístico de los datos ha requerido la codificación a través del programa IBM SPSS Statistics 20. Se detallan, a continuación, las distintas dimensiones de análisis:

Tabla 1. Análisis del narrador.

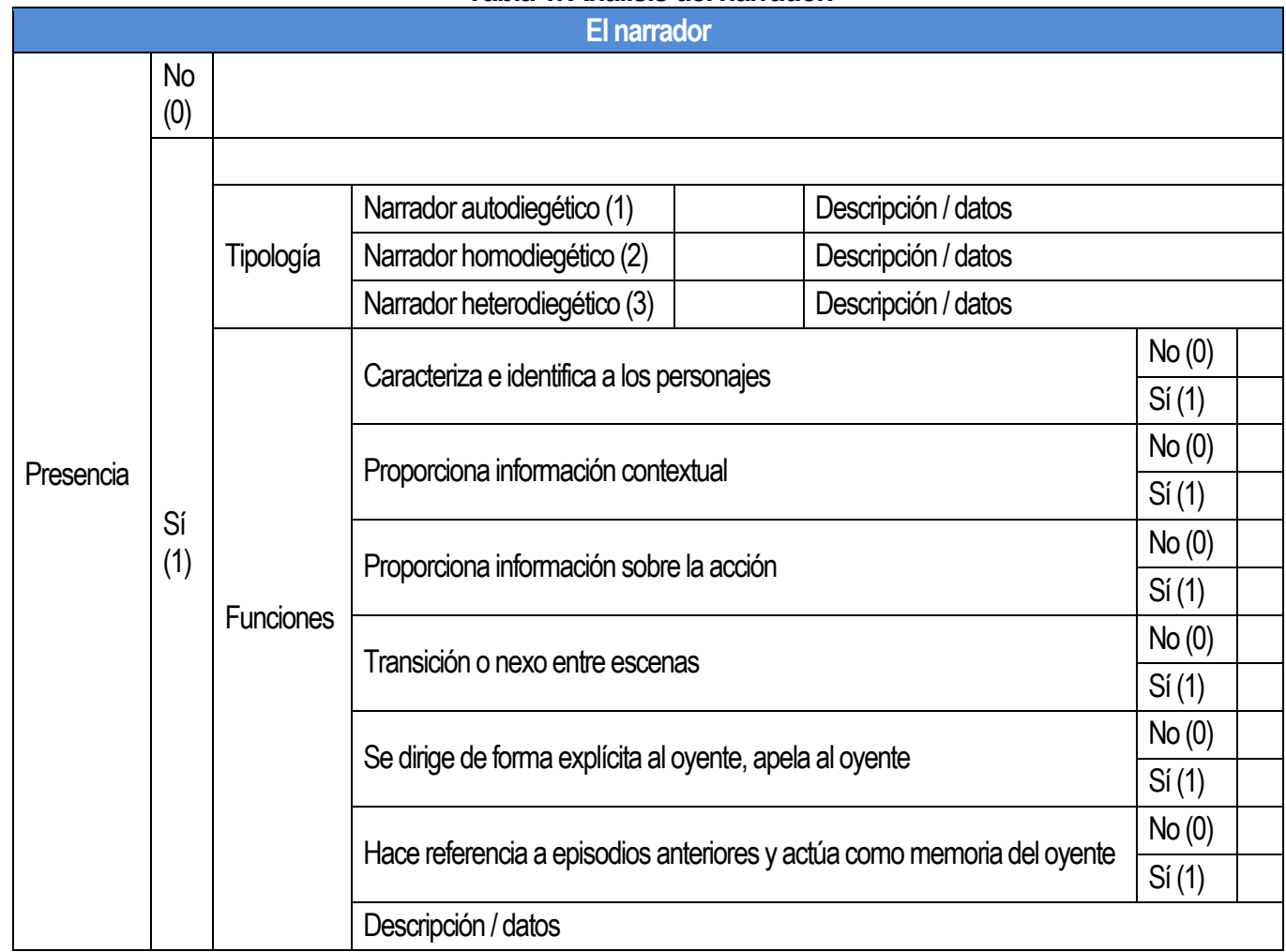

Fuente: elaboración propia (a partir de Kaplún, 1978; Genette, 1989; Camacho, 1999;

Barea, 2000; Balsebre, 2007; Rodero y Soengas, 2010).

\section{El narrador:}

\subsection{Presencia de narrador:}

se registrará la presencia $(\mathrm{S} i=1)$ o ausencia $(\mathrm{No}=0)$ de la figura del narrador en el guion de cada episodio. 


\subsubsection{Tipos de narrador (tipología de G. Genette):}

se ha tomado como referencia la tipología de narrador y características explicitadas en el primer epígrafe del artículo:

- Narrador autodiegético (se ha identificado como 1).

- Narrador homodiegético (se ha registrado como 2).

- Narrador heterodiegético (se ha establecido como 3).

Del mismo modo, la plantilla de análisis recoge una casilla denominada 'Descripción/datos' en la que se incluirán datos de especial relevancia en relación con cada tipo de narrador ${ }^{7}$.

1.1.2. Funciones del narrador (basadas en Rodero y Soengas (2010); Balsebre (2007: 190-191); Barea (2000); Camacho (1999); Kaplún (1978) y propuestas de la autora del artículo):

- Caracteriza e identifica a los personajes.

- Proporciona información contextual (tiempo, espacio, etc.) Sitúa la escena.

- Proporciona información sobre la acción.

- Ejerce de transición o nexo entre escenas.

- Se dirige de forma explícita al oyente, apela al oyente.

- Hace referencia a episodios anteriores y actúa como memoria del oyente.

${ }^{7}$ En el transcurso del análisis, junto a los tipos de narrador establecidos, se registró un caso de narrador múltiple u omnisciencia multiselectiva (Rodero y Soengas, 2010: 131), en el que «la acción se descubre a través de múltiples puntos de vista de distintos personajes de la historia, bien sean testigos o protagonistas de la misma». Este dato se especificó también en la casilla denominada 'Descripción/datos'. 
Se registrará la presencia $(\mathrm{S} i=1)$ o ausencia $(\mathrm{No}=0)$ de cada una de las funciones en el guion de cada episodio.

A continuación, se incluyen los resultados del estudio.

\section{Resultados}

En las páginas siguientes detallamos el porcentaje de presencia de la figura del narrador en la serie, e identificamos cuál es la tipología que predomina en los episodios que conforman la muestra, así como si existen diferencias significativas en los diversos periodos de emisión de Taxi Key en lo relativo a este aspecto. Por último, describimos las principales funciones del narrador en los guiones objeto de estudio.

\subsection{Presencia del narrador}

Los resultados obtenidos a partir del análisis de esta categoría evidencian que existe una tendencia mayoritaria a la aparición del narrador en los diversos guiones de Taxi Key, puesto que esta figura está presente en el 82,5 por ciento de los episodios (33 de 40), que supone mayoría significativa con $\mathrm{p}<, 001$.

Figura 1: Porcentaje de aparición del narrador.

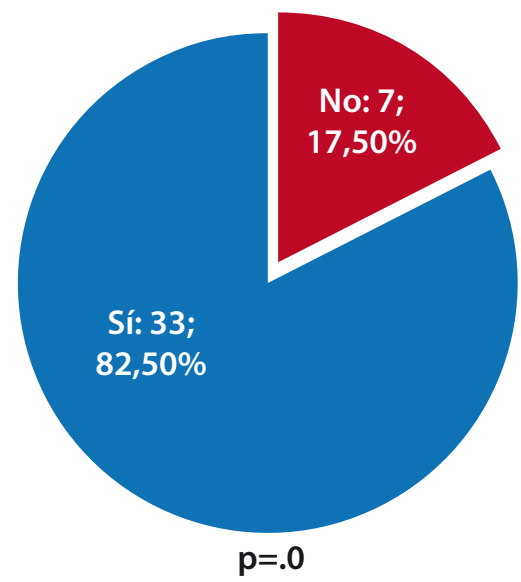

Elaboración propia mediante IBM SPSS Statistics 20. 
A pesar de que no se hayan manifestado diferencias entre los diversos periodos con $\mathrm{p}>, 05$ (ver tabla 2) se observa una cierta tendencia al incremento de la aparición del narrador en la segunda y tercera etapa (alrededor del 90 por ciento) frente a la primera época (66,7 por ciento), como muestran los datos representados en la tabla que se plasma a continuación.

Tabla 2: Presencia del narrador. Comparación por época.

\begin{tabular}{|c|c|c|c|c|c|}
\hline \multirow{2}{*}{ Variable } & \multirow{2}{*}{\multicolumn{2}{|c|}{ Descriptivos }} & \multicolumn{3}{|c|}{ Test de contraste } \\
\hline & & & Valor & $\overline{g l}$ & $\mathbf{p}$ \\
\hline Presencia del narrador $(\mathrm{N}=40)$ & Sí: 82,5\% (33) & No: $17,5 \%(7)$ & Chi2 $=16,900$ & 1 &, $000^{\star *}$ \\
\hline Épocal $(n=12)$ & $\begin{array}{r}66,7 \%(8) \\
875 \%(14)\end{array}$ & $33,3 \%(4)$ & & & \\
\hline Época II (n=16) & $87,5 \%(14)$ & $12,5 \%(2)$ & Chi $=2,881$ & 2 & NS \\
\hline Época III (n=12) & $91,7 \%(11)$ & $8,3 \%(1)$ & & & \\
\hline
\end{tabular}

\section{Fuente: elaboración propia.}

Al observar las cifras anteriores, y debido al elevado porcentaje de capítulos en los que interviene el narrador, resulta necesario profundizar en las principales modalidades de narrador que emergen de los guiones de Taxi Key. En dicho análisis se ha tomado como referencia la tipología de Gerard Genette (1989) citada al inicio del artículo y explicitada en el instrumento de análisis.

\subsection{Tipos de narrador}

Los datos resultantes relativos a los tipos de narrador revelan que en el 84,8 por ciento de los casos (28 de 33) interviene un narrador autodiegético, pues es el propio personaje protagonista, Taxi Key, quien además de ser partícipe de la diégesis (actúa como personaje central de la serie y capítulos) desempeña una función mediadora, ejerciendo el papel de narrador en más del 80 por ciento de los episodios en los que el guionista recurre a esta figura. Las cifras reflejan una clara mayoría significativa de esta modalidad con $\mathrm{p}<, 001\left(\mathrm{Chi}^{2}=39,818 ; 2 \mathrm{gl} ; \mathrm{p}=, 000\right)^{8}$, y se observa una tendencia

\footnotetext{
${ }^{8}$ Se han utilizado los tests Chi-cuadrado para comprobar si se registra mayoría significativa en la variable al analizar la muestra completa y para determinar si existen diferencias estadísticamente significativas en la comparación entre épocas.
} 
al incremento de este tipo de narrador, tanto en la segunda ( 92,9 por ciento) como en la tercera época $(90,9$ por ciento) frente a la primera (62,5 por ciento), aunque el dato no alcance significación estadística con $\mathrm{p}>, 05$.

En este caso, nos hallamos ante una variable que verifica la existencia de constantes significativas y tendencias comunes entre los diversos episodios de la muestra.

Figura 2: Tipos de narrador.

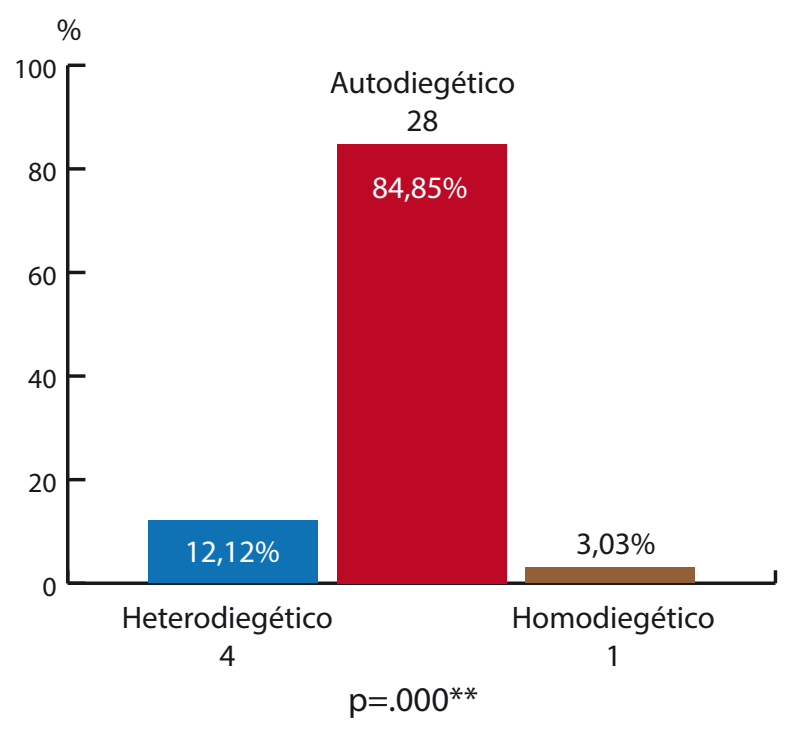

Elaboración propia mediante IBM SPSS Statistics 20.

A partir de estas cifras, se puede comprobar cómo el guionista otorga el protagonismo, también a través de su faceta de narrador, al personaje central de la serie: Taxi Key. El hecho de que el tipo de narrador predominante en los guiones seleccionados para esta investigación sea de carácter autodiegético supone que la focalización de la historia —que viene determinada a su vez por otros elementos- 
dependa en gran medida del personaje protagonista, ya que es este el responsable de narrar sus propias aventuras. Este tipo de sujeto de la enunciación empleado por Luis G. de Blain se torna como figura recurrente en la novela y cine negro (el investigador que protagoniza la novela o film negro o policiaco recuerda los casos que lideró y las experiencias que se desencadenaron de aquellos sucesos).

Como podrá comprobar el lector, en este epígrafe dedicado a los resultados se irán incluyendo fragmentos de guiones de distintos episodios de la serie con los que se pretende corroborar lo aportado en el análisis.

Fragmento guion 1: Narrador autodiegético: Taxi Key.

TAXI: (EXPLICANDO) En cierta ocasión, una casa productora de películas ofreció a Norah un contrato para que escribiese un guión de misterio inspirado en alguna de mis aventuras. De modo que tuvimos que personarnos en los Estudios cinematográficos. Confieso que me desagradaba dar aquel paso. Tenía la convicción de que surgirían dificultades y que, sin duda alguna, habría algún mentecato que le metería a Norah en la cabeza la idea de que había nacido para "estrella» del cine. De todas formas, penetramos en el Estudio y un botones nos condujo a uno de los platós y...

\section{FONDO=ENCADENA CON MURMULLOS DISCRETOS EN DISCO=}

Guion: 10 de enero de 1953, 21.05 h. Episodio: Crimen en el plató.

Como se puede inferir de lo apuntado anteriormente, el que el inconfundible Taxi Key se halle inmerso en el universo de la historia y a su vez ejerza el papel de narrador condiciona el grado de conocimiento que dispone de la misma, así como el tono y la posición adoptada al recordarla. De esta forma, la marcada personalidad y punto de vista del personaje central de la serie se hacen extensivos a sus intervenciones como narrador, recurso que aparece de forma especialmente evidente en aquellos fragmentos en los que se hace eco de una vivencia personal o algún momento de su vida del que forman parte otros personajes principales como Norah o Glossop. De especial interés resultan las intervenciones que se sitúan al inicio de los episodios. 
Fragmento guion 2: Narrador autodiegético: Taxi Key.

TAXI: (EXPLICANDO) Como sea que las circunstancias nos impidieron tomar el avión para Londres, en nuestro viaje a Europa, compramos pasaje en un transatlántico. Debo decirles que nuestra intención al iniciar este viaje no es otra que disfrutar de un descanso y, al propio tiempo, conocer las principales capitales europeas y, sobre todo, Barcelona, donde mis aventuras son radiadas.

Pues bien, como les decía, nos embarcamos, y el inefable Glossop se obstinó en acompañarnos. Como al muchacho no le viene de un millón de dólares más o menos, aquel viaje era para él lo que para nosotros coger el metro.

Guion: 23 de septiembre de 1950, 21.05 h. Episodio: Espías a bordo.

Fragmento guion 3: Narrador autodiegético: Taxi Key.

TAXI: Todo ocurrió a causa de la testarudez de Norah... Recuerdo que habíamos estado cenando en su pisito y yo me ocupaba de secar la vajilla que ella fregaba. De pronto me dijo:

NORAH: Estoy pensando que me convendría pasar unas vacaciones fuera de la ciudad.

Guion: 29 de mayo de 1949, 17.30 h. Episodio: El organista fantasma.

Del mismo modo, a pesar de que podamos identificar al narrador autodiegético y al personaje protagonista como un único sujeto, ambos cuentan con un nivel de información desigual en lo relativo al enigma que se plantea en cada guion, puesto que se encuentran distanciados en el tiempo. El Taxi Key-narrador dispone de un porcentaje de información superior al Taxi Key-personaje, ya que se sitúa en un momento futuro respecto a los personajes que protagonizan el episodio semanal y, por tanto, al haber vivido en primera persona las aventuras que relata conoce de forma detallada lo sucedido (no debemos olvidar tampoco el periodo temporal en el que se sitúa la audiencia y la información de la que dispone gracias a los diálogos y el narrador). En este contexto, el guionista decide de qué manera dosificar los datos que el narrador proporciona a los oyentes, qué tipo de informaciones facilitar y en qué momento. 
Fragmento guion 4: Narrador autodiegético: Taxi Key.

TAXI: Ayúdame a buscarla

KELLY: ¡Sí, sí, hay que encontrarla!

NORA: (ALGO LEJOS) ¡Aquí, aquí! (GRITO DE TERROR)

\section{SONIDO: FONDO SE APIANA}

TAXI: El cuerpo de Elsa yacía entre los bancos, cerca de la estufa de hierro que había en un rincón. La habían asesinado golpeándola en la frente con el mismo martillo que el culpable utilizó para matar al perro. El doctor Peabody observó:

SONIDO: SIN PAUSA. CESA FONDO

Guion: 11 de mayo de 1957, 20.00 h. Episodio: El tañido de la muerte.

Será únicamente al final de cada capítulo cuando el narrador autodiegético, Taxi $K e y$-personaje y la audiencia dispongan del mismo grado de información.

En definitiva, la narración en primera persona favorece la revelación de los diversos rasgos y facetas del personaje protagonista. Reafirma la naturalidad y expresividad de Taxi Key en sus múltiples actuaciones y fomenta la complicidad con los oyentes, a los que guía en el transcurso del episodio a través de su carismática y particular visión de lo acontecido. En este sentido, en lo que al narrador autodiegético se refiere, sólo es preciso puntualizar que en los dos capítulos de la muestra en los que no interviene Taxi Key, serán los otros dos personajes principales los que adopten el papel de narrador, en una ocasión Glossop y en la otra Norah (se han considerado autodiegéticos porque adoptaban el papel protagonista en ausencia de Taxi). 
Fragmento guion 5: Narrador autodiegético: Glossop.

\section{SONIDO: FONDO FUNDE}

GLOSSOP: Todo aquello me sucedió por hacer lo que mi padre me indicaba en un telegrama. Ir a ver a cierto astrónomo llamado Heaslip y contratar sus servicios para la fábrica de instrumentos de precisión de papá. Heaslip trabajaba en el observatorio Drum, situado en un pueblo llamado Starlington. Llegué de noche y no me hizo gracia ir al laboratorio, perdido en el bosque, en medio de una medrosa obscuridad.

Entonces los acontecimientos se sucedieron en el orden siguiente: Encontré la puerta del observatorio abierta y entré en un vestíbulo vacío y parcamente alumbrado; las luces se apagaron de pronto y unos ruidos sospechosos en lo que supuse sería la sala del

Telescopio: un golpe y pasos precipitados. Alumbrándome con mi linterna entré en la sala del telescopio y, ¡cátate!, allí, tendido en el suelo, había un hombre al que le habían hundido la cabeza con un pedrusco. Supuse que el asesino había escapado por el abierto ventanal de la estancia y salí por él... vi los faros de un auto entre los árboles del bosquecillo y, suponiendo que en él se escapaba el criminal, corrí para darle alcance. Pero, claro, el auto corrió más que yo. Me detuve y estaba tratando de recuperar la respiración cuando vi una sombra que se me acercaba por el camino. Le enfoqué con mi linterna. Era un joven que llevaba una bufanda de seda blanca en el cuello y un paquete debajo del brazo.

El joven me dijo....

SONIDO: CANTO DE GRILLOS EN LA NOCHESONIDO: SIN PAUSA. CESA

Guion: 29 de octubre de 1964, 20.00h. Episodio: La aventura del observatorio.

A pesar del predominio del narrador autodiegético en esta serie radiofónica, los resultados manifiestan la presencia de otro tipo de narradores como el heterodiegético, al que el guionista recurre en el 12,1 por ciento de los episodios de la muestra (cuatro), ubicados esencialmente en la primera etapa de la serie. La extensión y número de intervenciones de esta clase de narrador varía en función de los guiones, pero su presencia es más limitada que la reflejada en la modalidad autodiegética. A esta categoría pertenece el narrador del primer episodio de la serie. 
Fragmento guion 6: Narrador heterodiegético.

\section{MÚSICA DE FONDO}

NARRADOR: Una carretera en las cercanías de Hollywood, y dos autos que corren por ella a toda velocidad.

\section{MOTOR AUTO= SE APIANA}

NARRADOR: El que va delante es un taxi de motor potente. El coche que va detrás es un pequeño dos plazas de turismo que se empeña en adelantarle.

\section{CLAXON INSISTENTE}

NARRADOR: El chófer del taxi es un joven fuerte y robusto, de cara burlona, al que los claxonazos parecen dejar indiferente, hasta que por último dice...

Guion: 2 de octubre de 1948, 22.30 h. Episodio: Taxi Key interviene.

En el fragmento anterior se puede apreciar de qué manera este observador externo, que no participa de la diégesis, se limita a describir la escena. Muestra un grado de implicación mínima y un discurso distante. Se muestra manifiestamente aséptico, frente a la frescura e inevitable visión subjetiva aportada por el narrador autodiegético. En otros episodios, como el que se incluye a continuación, la presencia del narrador heterodiegético es prácticamente inexistente.

Fragmento guion 7: Narrador heterodiegético.

\section{MOTOR= ENCADENA CON MÚSICA DE FONDO= SE APIANA}

(5)

BLANCH: Cuando llegaron al número 213 de la Avenida de los Alerces, la noche había caído y el solitario barrio parecía sumido en misteriosas negruras.

FONDO $=$ ENCADENA CON MOTOR AUTO $=$ CESA

Guion: 12 de febrero de 1949, 23.10 h. Episodio: Taxi Key, otra vez taxista.

No obstante, dentro de esta tipología podemos distinguir diferentes matices en función de la etapa a la que se circunscriba, como pone de manifiesto el ejemplo que se explicita a continuación, cuya descripción del lugar, la acción y los personajes se sitúa cercana a lo literario. 
Fragmento guion 8: Narrador heterodiegético.

(2)

SONIDO: FONDO MUSICAL ENCADENA CON MOTOR AUTO. SE APIANA

NARRADOR: El lujoso automóvil avanzaba velozmente por la carretera brillante de humedad. Caía una fina llovizna en el gris atardecer y, allí al fondo, el horizonte se encendía de vez en cuando con el resplandor de un relámpago.

Junto a Taxi Key, en el interior del auto, viajaba un individuo de aspecto pomposo y que, por los aires de gran señor que se daba se comprendía enseguida que no pasaba de ser un lacayo. En efecto era el mayordomo De Lord Savern. Se llamaba Benson y su compostura era tanta que solo la perdió un instante, cuando el chófer de librea tomó un brusco viraje sobre dos ruedas. Benson explicó a Taxi Key:

BENS: Hemos recurrido a usted porque se trata de un asunto que se aparta de lo normal..., y nos han dicho que su especialidad son los casos raros y extravagantes.

\section{Guion: 7 de abril de 1962, 20.00 h. Episodio: La aventura de la estatuilla egipcia.}

Asimismo, de forma esporádica, se ha registrado en una ocasión el empleo de un narrador homodiegético (3,0 por ciento). En este caso, se ha catalogado como narrador homodiegético al propio Taxi Key, al tratarse de un capítulo protagonizado por Glossop y en el que Taxi, que se sitúa como instancia de la enunciación, interviene en la diégesis, pero no como personaje central en la historia.

\section{Fragmento guion 9: Narrador homodiegético.}

TAXI: En cierta ocasión, Glossop heredó una pequeña fortuna. A los millonarios suelen ocurrirle esas cosas. Ahora bien, el testamento era de los que suelen provocar crímenes... Sí, sí, crímenes.

Guion: 19 de noviembre de 1955, 21.00 h. Episodio: Glossop y su asesino.

Por último, resulta de interés destacar que en uno de los capítulos que conforman la muestra de estudio el guionista recurre a un narrador múltiple al inicio del capítulo (de forma excepcional), interpretado por Taxi y Glossop. Ambos recuerdan, a través de un fresco diálogo, qué les sucedió en una ocasión. 
Fragmento guion 10: Narrador múltiple.

\section{FONDO - SE APIANA}

TAXI: No sé cómo se las compone Glossop, pero siempre se mete en algún lío..., incluso cuando no se lo propone. Recuerdo, por ejemplo, aquella ocasión en que se paseaba tranquilamente por el parque....

GLOSSOP: ...... Sí, por el parque, sin pensar en nada malo, con la mente tan limpia como la de un recién nacido, escuchando el gorgeo de los pajaritos...

\section{CANTO DE PÁJAROS - SE APIANAN}

GLOSSOP: ¿O sería el croar de las ranas en el estanque lo que yo escuchaba?

\section{CANTO DE PÁJAROS - ENCADENA RÁPIDAMENTE CON CROAR DE RANAS - FUNDEN LENTAMENTE}

GLOSSOP: Sí, me paseaba escuchando el croar de las ranas... o tal vez el canto de los pajaritos...

TAXI: Bueno, Glossop, no te pongas pesado ¡Abrevia, por favor!

GLOSSOP: De acuerdo.... ¡Ejem!... Me paseaba yo por aquel tranquilo y romántico parque ciudadano...

\section{RUIDO DE TRÁFICO SE APIANA}

GLOSSOP: Aquel parque ciudadano tan romántico y... Bueno, eso... y, de pronto... ¡Ah, de pronto!... Verán, yo iba sin pensar en nada, como de costumbre, cuando súbitamente....

\section{FRENAZO DE AUTO}

JOE: ¡Vamos, suba al auto!

Guion: 25 julio de 1953, 21.05 h. Episodio: El caso del secuestro.

Por tanto, a la luz de los resultados, podemos afirmar que Luis G. de Blain no recurre a una única modalidad de narrador, sino que opta por diferentes instancias de la enunciación, entre las que predomina el narrador autodiegético. Si observamos con detenimiento la intervención del narrador en los episodios de la muestra, podemos comprobar cómo en el primer año de la serie se alterna la intervención del narrador heterodiegético con los capítulos en los que se prescinde de la figura del narrador, práctica que se mantiene también a principios de 1949. De los capítulos que conforman la muestra, es a partir del capítulo que data de mayo de 1949 el momento en el que la figura del narrador autodiegético, interpretado por Taxi Key, 
adquiere gran relevancia. Posteriormente, se registra algún episodio sin narrador, pero primará la presencia de la modalidad autodiegética.

Tabla 3: Tipos de narrador. Comparación por época.

\begin{tabular}{|c|c|c|c|c|c|c|}
\hline \multirow{2}{*}{ Variable } & \multirow{2}{*}{\multicolumn{3}{|c|}{ Descriptivos }} & \multicolumn{3}{|c|}{ Test de contraste } \\
\hline & & & & Valor & gI & $p$ \\
\hline $\begin{array}{l}\text { Tipología del } \\
\text { narrador ( } N=33)\end{array}$ & $\begin{array}{r}\text { Autodiegético: } \\
84,8 \% \text { (28) }\end{array}$ & $\begin{array}{r}\text { Homodiegético: } \\
3,0 \% \text { (1) }\end{array}$ & $\begin{array}{r}\text { Heterodiegético: } \\
12,1 \%(4)\end{array}$ & $\mathrm{Chi}^{2}=39,818$ & 2 &, $000^{* *}$ \\
\hline Época I (n=8) & $62,5 \%(5)$ & $0 \%(-)$ & $37,5 \%(3)$ & & & \\
\hline Época II (n=14) & $92,9 \%(13)$ & $7,1 \%(1)$ & $0 \%(-)$ & Chi $=5,273$ & 6 & $\begin{array}{r}, 509 \\
\text { NS }\end{array}$ \\
\hline Época III $(n=11)$ & $90,9 \%(10)$ & $0 \%(-)$ & $9,1 \%(1)$ & & & \\
\hline
\end{tabular}

\section{Fuente: elaboración propia.}

\subsection{Funciones del narrador}

El análisis realizado en la presente investigación nos ha permitido constatar cómo Luis G. de Blain recurre esencialmente a la figura del narrador con el objetivo de contextualizar informaciones básicas que requiere conocer el oyente, referentes al lugar, la acción, los personajes o el tiempo, así como favorecer la transición entre escenas. A diferencia de lo que sucede en otras ficciones radiofónicas en las que se observa un empleo excesivo de la figura del narrador, el guionista de esta serie lleva a cabo un uso racional del mediador de la historia en las diversas etapas de la serie, priorizando la construcción dramática de la acción a través de los diálogos de los personajes.

De forma detallada, del estudio de las funciones del narrador se desprenden los resultados siguientes: 
index॰comunicación| número monográfico 9(2), 2019 Radioteatro

Tabla 4: Narrador. Funciones. Comparación por época.

\begin{tabular}{|c|c|c|c|c|c|}
\hline \multirow{2}{*}{ Variable } & \multicolumn{2}{|c|}{ Descriptivos } & \multicolumn{3}{|c|}{ Test de contraste } \\
\hline & Sí & No & Valor & $\mathrm{gl}$ & $p$ \\
\hline Caracteriza e identifica a los personajes ( $\mathrm{N}=33$ ) & $93,9 \%(31)$ & $6,1 \%(2)$ & $\mathrm{Chi}^{2}=25,485$ & 1 &, $000^{* *}$ \\
\hline Épocal $(n=8)$ & $87,5 \%(7)$ & $12,5 \%(1)$ & & & \\
\hline Época II (n=14) & $92,9 \%(13)$ & $7,1 \%(1)$ & Chi2 $=1,856$ & 2 &, 395 NS \\
\hline Época III (n=11) & $100 \%(11)$ & $0 \%(-)$ & & & \\
\hline Proporciona información contextual (N=33) & $100 \%(33)$ & $0 \%(-)$ & - & - & - \\
\hline Proporciona información sobre la acción ( $\mathrm{N}=33$ ) & $100 \%(33)$ & $0 \%(-)$ & - & - & - \\
\hline Actúa como nexo entre escenas (N=33) & $93,9 \%(31)$ & $6,1 \%(2)$ & $\mathrm{Chi}^{2}=25,485$ & 1 &, $000^{* \star}$ \\
\hline Épocal $(n=8)$ & $100 \%(8)$ & $0 \%(-)$ & & & \\
\hline Época II (n=14) & $85,7 \%(12)$ & $14,3 \%(2)$ & Chi $=3,606$ & 2 & $165 \mathrm{NS}$ \\
\hline Época III (n=11) & $100 \%(11)$ & $0 \%(-)$ & & & \\
\hline Apela al oyente $(\mathrm{N}=33)$ & $24,2 \%(8)$ & $75,8 \%(25)$ & Chil $=8,758$ & 1 &, $003^{* \star}$ \\
\hline Épocal $(n=8)$ & $25,0 \%(2)$ & $75,0 \%(6)$ & & & \\
\hline Época II (n=14) & $35,7 \%(5)$ & $64,3 \%(9)$ & Chi2=2,606 & 2 & $272^{\text {NS }}$ \\
\hline Época III (n=11) & $9,1 \%(1)$ & $90,9 \%(10)$ & & & \\
\hline Hace referencia a episodios anteriores ( $\mathrm{N}=33$ ) & $0 \%(-)$ & $100 \%(33)$ & - & - & - \\
\hline
\end{tabular}

\section{Fuente: elaboración propia.}

Las cuatro primeras funciones, tipificadas en la tabla anterior, hacen referencia a los cometidos básicos que suele desempeñar el narrador en la serie. Los datos revelan que en el cien por cien de los episodios en los que aparece la figura del narrador (33 de 40) éste proporciona información contextual (sobre el lugar en el que se desarrolla la acción, la distribución del espacio o el tiempo, así como los antecedentes de la historia), al menos en alguna de sus intervenciones. Asimismo, en la totalidad de capítulos en los que está presente, el narrador aporta datos sobre la acción (física o emocional). Resulta especialmente significativa la manera en que el guionista presenta la situación inicial de los episodios, ofreciendo este tipo de datos esencialmente a través del narrador autodiegético. Fragmentos que revelan un característico estilo, que se convierte en una de las señas de identidad de la serie. 
Fragmento guion 11: Funciones del narrador.

TAXI: (EXPLICANDO) Nos hallábamos Norah y yo en Monte Carlo. Desde luego, la temporada había terminado..., pero todavía quedaba allí una pequeña colonia de extranjeros, de esos que gustan del Mediterráneo y de los Casinos donde se juega fuerte. Nos habíamos hospedado en un buen hotel y, naturalmente, Norah se fue de compras. Yo me entretuve unos momentos en el bar y cuando subí a mi habitación...

FONDO $=$ ENCADENA CON PORTAZOS

Guion: 3 de febrero de 1950, 21.05 h. Episodio: Aventura en Monte Carlo.

Fragmento guion 12: Funciones del narrador.

SONIDO: FONDO SE APIANA

TAXI: Los sucesos que voy a referirles acaecieron durante mi estancia en Francia. Yo había trabado amistad con un importante comisario de la Policía Judicial llamado Bencolin. Hallándome en París, Bencolin me citó en su despacho. Cuando llegué, el policía se disponía a salir y me dijo precipitadamente.

BENCO: Hay un hombre cuya vida está en grave peligro. Mi misión consiste en protegerle.

TAXI: ¿De quién se trata?

BENCO: Del duque Raúl de Saligny, el famoso deportista. Pero no tenemos un minuto que perder... ¡Me está esperando en casa de Fenelli!

Guion: 21 de septiembre de 1957, 20.00 h. Episodio: Asesino en la noche.

Merecen especial atención las referencias al escenario realizadas por el narrador al comienzo del capítulo, en las que resulta habitual que se especifique tanto la ubicación general en la que transcurrirá el conflicto episódico (Hollywood, Washington, Londres, etc.), como el espacio concreto en el que comienza la acción (por ejemplo, la habitación de un hotel, el interior de un automóvil, etc.). Datos que contribuyen a que el oyente disponga de la información necesaria para situar la escena. 
Fragmento guion 13: Función narrador: proporcionar información sobre el escenario.

\section{SONIDO: FONDO MUSICAL. SE APIANA}

TAXI: Nos encontrábamos Norah y yo en una de las islas del protectorado de los Estados Unidos en los mares del Sur y teníamos que trasladarnos a una localidad llamada Fenix, el único medio de locomoción era un pequeño y viejo autocar. Una tormenta nos alcanzó en pleno descampado y...

\section{SONIDO. FONDO ENCADENA CON MOTOR DE AUTO. SE APIANA}

Guion: 7 de junio de 1958, 20.00 h. Episodio: Un tiro en la noche.

De manera general, el estudio revela que el narrador aporta información sobre el escenario en la totalidad de los capítulos en los que aparece, es decir, el 82,5 por ciento de las veces (33 de los 40 guiones estudiados), dato que supone mayoría significativa con $\mathrm{p}<, 001\left(\mathrm{Chi}^{2}=16,900 ; 1 \mathrm{gl} ; \mathrm{p}=, 000\right)$, sin que haya diferencias reveladoras al comparar unas épocas con otras con $\mathrm{p}>, 05$.

Tabla 5: Narrador. Escenarios. Recreación. Comparación por época.

\begin{tabular}{|c|c|c|c|c|c|}
\hline \multirow{2}{*}{ Variable } & \multicolumn{2}{|c|}{ Descriptivos } & \multicolumn{3}{|c|}{ Test de contraste } \\
\hline & Sí & No & Valor & gl & $p$ \\
\hline Narrador $(\mathrm{N}=40)$ & $82,5 \%(33)$ & $17,5 \%(7)$ & $\mathrm{Chi}^{2}=16,900$ & 1 &, $000^{* *}$ \\
\hline $\begin{array}{l}\text { Época I }(n=12) \\
\text { Época II }(n=16) \\
\text { Época III }(n=12)\end{array}$ & $\begin{array}{r}66,7 \%(8) \\
87,5 \%(14) \\
91,7 \%(11)\end{array}$ & $\begin{array}{r}33,3 \%(4) \\
12,5 \%(2) \\
8,3 \%(1)\end{array}$ & $\mathrm{Chi}^{2}=2,881$ & 2 & ,237 NS \\
\hline$N S=$ no significativo $(p>, 050)$ & \multicolumn{5}{|c|}{${ }^{*}$ Significativo al $5 \% \quad$ ** Altamente Significativo al $1 \%$} \\
\hline
\end{tabular}

Fuente: elaboración propia.

De igual modo, una de las funciones fundamentales que ejerce el narrador en el transcurso de la serie es la de actuar de nexo o transición entre escenas, la cual desempeña en el 93,9 por ciento de los capítulos en los que interviene; dato significativo con $\mathrm{p}<, 001\left(\mathrm{Chi}^{2}=25,485 ; 1 \mathrm{gl} ; \mathrm{p}=, 000\right)$, sin que haya cambios entre épocas con $\mathrm{p}>, 05$. La mediación del narrador en estos casos implica esencialmente el cambio de espacio y tiempo en el que se desarrolla la acción. En este sentido, el narrador posibilita las transiciones temporales en 30 de los 35 capítulos (85,7 por ciento) en los que la dimensión tiempo se construye a partir de diégesis impura, por 
lo que el empleo de la elipsis funcional a través de esta figura es mayoritario con $\mathrm{p}<, 001\left(\mathrm{Chi}^{2}=17,857 ; 1 \mathrm{gl} ; \mathrm{p}=, 000\right)$. Sin embargo, al contrastar entre etapas, se observa un cambio relevante con $\mathrm{p}<, 05\left(\mathrm{Chi}^{2}=7,237 ; 2 \mathrm{gl} ; \mathrm{p}=, 027\right)$, ya que el empleo de este recurso es menor en la primera época (63,6 por ciento) que en las otras dos (92,3 por ciento y cien por cien), dato que aparece íntimamente relacionado con el menor grado de presencia del narrador (esencialmente de carácter autodiegético) en el primer periodo en comparación con el segundo y el tercero.

Fragmento guion 14: Función narrador: actuar de nexo o transición entre escenas.

\section{SONIDO: FONDO MUSICAL. SE APIANA}

TAXI: Llegamos a Washington al anochecer porque nos había retrasado una fuerte tormenta...

\section{(CESA MÚSICA)}

GLOSSOP: Escucha, Taxi, me parece que lo mejor será que nos detengamos en el primer hotel que nos encontremos.... ¡Estoy hecho astillas de tanto viajar por carretera!... En el hotel podremos tomar un baño caliente, arreglarnos... y llegar como nuevos a casa del notario.

TAXI: Está bien, Glossop, como quieras.

\section{SONIDO: MUSICA. SE APIANA}

TAXI: (EXPLICANDO) Nos detuvimos en un pequeño hotel que encontramos en los suburbios de la ciudad. Un portero soñoliento nos atendió de mala gana. Le dio la habitación número 17 a Glossop y a mí, la veinte. Me tendí un rato encima de la cama para relajar los músculos. Quise fumar y me di cuenta de que se me habían acabado los pitillos, de modo que salí al pasillo, bajé al vestíbulo... y me encontré con un portero que no era el mismo que nos atendió a nuestra llegada...

Guion: 19 de noviembre de 1955, 21.00 h. Episodio: Glossop y su asesino. 
indexocomunicación| número monográfico 9(2), 2019 Radioteatro

Fragmento guion 15: Función narrador: actuar de nexo o transición entre escenas.

TAXI: Bueno, bueno, bueno... ¡Ejem! Aquí tiene su artillería, Matew. He decidido confiar en usted... Quédese en este barco, mientras mi esposa y yo vamos a reunirnos con la señorita Genoveva... ¡Vamos, Norah!

\section{SIRENA DE BARCO, LEJANA= ENCADENA CON FONDO SE APIANA Y FUNDE}

TAXI: Al llegar al camarote Genoveva, en el "Monticello", nos llevamos la gran sorpresa: ¡La chica no estaba allí! ¡Había desaparecido!

Guion: 30 de octubre de 1954, 21.05 h. Episodio: Cementerio de barcos.

A pesar de que las intervenciones del narrador no suelen ser muy extensas, existen algunas excepciones en determinados capítulos, como demuestra el fragmento que se incluye a continuación. En este caso se prioriza dicho recurso para hacer avanzar la trama del episodio. 
Fragmento guion 16: Intervención extensa del narrador.

TAXI: (EXPLICANDO) Después de desembarcar a Monk, estuve haciendo carreras hasta cerca de las doce. A dicha hora conduje mi taxi hasta el periódico. Al detenerme delante de la marquesina observé que el portero brillaba por su ausencia. En aquel momento, dos hombres cruzaron la acera y se metieron en mi taxi antes de que yo tuviera tiempo de fijarme en ellos. Uno de los hombres me ordenó..

DUNCAN: A la Estación Central.

TAXI: (EXPLICANDO) Aquella voz me pareció vagamente familiar. Intenté distinguir en el espejo retrovisor el rostro de mis clientes, pero estos permanecían callados, meditabundos y con el sombrero calado hasta las orejas. Al llegar a la estación central, uno de ellos me dijo: "Mi amigo se apea aquí, pero usted va a conducirme al Hollywood Boulevard y Avenida Helrene...! Adiós, Charly!" ...Aquella no era la voz de antes... Uno de los viajeros saltó de mi taxi y entró como una centella en la Estación. Yo estaba seguro de que el hombre que se había quedado dentro del coche era el mismo que habló primero..., pero mi obligación era llevarlo a donde me había dicho y dejarme de deducciones.

\section{FONDO=ENCADENA CON MOTOR AUTO= SE APIANA}

TAXI: (EXPLICANDO) Conduje a buena marcha hasta llegar a una señal luminosa que me obligó a disminuir la marcha. Había allí bastante luz y por el retrovisor distinguí el rostro de mi cliente... ¡Cielos, era el individuo que unas horas antes llevaba un cadáver en su auto!... Pisé el acelerador y conduje tan rápidamente como pude hasta el Cuartel General de Policía.

Guion: 2 de enero de 1954, 21.05 h. Episodio: Fin de año en un Taxi.

Asimismo, en un 93,9 por ciento de los episodios en los que aparece la figura del narrador, al menos en una ocasión por capítulo, el sujeto de la enunciación o bien caracteriza a los personajes (fundamentalmente personajes principales y episódicos), aportando una descripción visual del personaje o algún rasgo que lo identifique, o se limita a incorporarlos a escena. Esta cifra supone mayoría significativa con $\mathrm{p}<, 001$ $\left(\mathrm{Chi}^{2}=25,485 ; 1 \mathrm{gl} ; \mathrm{p}=, 000\right)$, sin que se aprecien cambios entre épocas con $\mathrm{p}>, 05$. 
indexecomunicación| número monográfico 9(2), 2019 Radioteatro

Fragmento guion 17: Narrador. Caracterización personaje.

\section{FONDO $=$ SE APIANA}

TAXI: Cierta vez conocí a un tal Conolly, un viejo detective que no tenía suerte. Me era simpático. Por eso cuando me escribió pidiendo mi ayuda, no tuve inconveniente en acudir a echarle una mano.

MOTOR AUTO = SE APIANA

Guion: 30 de octubre de 1954, 21.05 h. Episodio: Cementerio de barcos.

Por último, es necesario que hagamos alusión a dos de las funciones vinculadas especialmente al género que nos ocupa, la serie radiofónica, y al propio estilo de Aventuras de Taxi Key, las tipificadas como: hace referencia a episodios anteriores y apela al oyente. Al diseñar el estudio se pretendía comprobar si, al igual que sucede en los seriales radiofónicos, en este espacio el narrador actuaba como memoria del oyente, recordando algún suceso o dato acaecido en episodios anteriores; puesto que, a pesar de la independencia de cada trama episódica, los resultados evidencian otros elementos de continuidad dramática, como la presencia de tramas horizontales. En este sentido, los resultados reflejan que en ningún episodio el narrador, independientemente de su tipología, hace referencia a capítulos anteriores, recurso que el guionista sí emplea en determinados casos en el interior de los diálogos.

A diferencia de lo que sucede con la función anterior, el narrador autodiegético apela a los oyentes de forma explícita en ocho capítulos (24,2 por ciento) de los analizados. Función que fomenta la complicidad entre audiencia y protagonista, que en este caso desempeña el papel de narrador. Se dirige a ellos en tercera persona del plural y con términos como «señores», «debo decirles», «como les decía», etc. 
Fragmento guion 18: Apelación a los oyentes.

TAXI: (NARRA) Pues sí, señores, huyendo del frío, Norah y yo decidimos concedernos unas pequeñas vacaciones en una localidad del Sur de California, cerca de la frontera mejicana. Aquel pueblecito se llamaba Piñon y estaba como perdido en el desierto. Habíamos alquilado una casita en las afueras. Estaba yo tomando el fresco en la veranda, cuando...

SONIDO: FONDO: ENCADENA CON CANTO PÁJAROS

Guion: 10 de enero de 1963, 20.00 h. Episodio: La aventura de los sospechosos sin coartada.

En definitiva, el guionista recurre a la figura narrador con fines muy concretos que contribuyen a que el oyente disponga de un mayor número de datos de tipo contextual o en relación con los personajes, que la historia avance o que se intensifique el suspense al interrumpir una situación de máxima tensión, mostrando incluso guiños de complicidad explícita en determinados episodios. Su presencia no ralentiza el ritmo de la historia, debido esencialmente a su carácter mayoritariamente autodiegético y a que el guionista ubica sus intervenciones en momentos idóneos de cada trama episódica.

\section{Conclusiones}

De los resultados explicitados en páginas previas se extraen las siguientes conclusiones:

1. La presencia de la figura del narrador alcanza la mayoría significativa en los episodios de Taxi Key, observándose una tendencia al incremento en la segunda y tercera etapa de emisión de la serie.

2. El narrador autodiegético aparece como tipo de narrador más frecuente. Existe una propensión en alza de la intervención de esta modalidad de narrador tanto en la segunda como en la tercera época de Taxi Key.

- El predominio del narrador autodiegético implica que el protagonismo de Taxi Key se haga extensivo a la focalización y mediación de la historia al ser el personaje central de la serie el encargado de narrar en primera persona sus propias aventuras. El relato de los capítulos a través de esta técnica reafirma la personalidad, expresividad y naturalidad de Taxi Key, 
que se hace evidente de forma marcada al inicio de los episodios a través de su carismática y particular visión de lo acontecido. Favorece la complicidad con los oyentes, a los que llega a dirigirse de forma explícita. Se aprecian elementos constantes en el modo de narrar la historia al comienzo de determinados episodios.

- Otros personajes principales, como Norah o Glossop, desempeñan el papel de narrador autodiegético en ausencia de Taxi.

3. Junto a la modalidad autodiegética, en la serie Taxi Key aparecen representados otros tipos de narrador como el heterodiegético, segundo tipo de narrador en número de apariciones que cuenta con una presencia reducida en el conjunto de la serie. Su implicación es mínima, se muestra aséptico y distante. La extensión de sus intervenciones y número de apariciones varía en función del episodio.

4. El narrador homodiegético y el narrador múltiple aparecen de forma esporádica. Su presencia incrementa la diversidad de tipos de narrador empleada por el guionista.

5. Proporcionar información contextual, sobre el escenario, el tiempo y en torno a la acción, actuar de nexo y transición entre escenas y caracterizar a los personajes o incorporarlos a escena son las funciones del narrador que prevalecen en los episodios de Taxi Key. No existen cambios significativos entre etapas. Resulta frecuente que el narrador proporcione al oyente en el inicio del episodio los datos clave que le permitirán contextualizar la historia. En ningún guion objeto de estudio el narrador ha desempeñado la función de hacer referencia a episodios anteriores, independientemente de su tipología. En determinados capítulos de la serie el narrador autodiegético apela de forma explícita a los oyentes, función que intensifica la relación creada por el autor entre el protagonista (en este caso en la figura del narrador) y su audiencia.

6. Los guiones de Taxi Key revelan un empleo racional de la figura del narrador en las diversas etapas de la serie, al priorizarse la construcción dramática de la acción a través de los diálogos de los personajes. Su presencia no ralentiza el ritmo de la historia, debido esencialmente a su carácter mayoritariamente autodiegético. 


\section{Referencias bibliográficas}

AGUILERA, M. y ARQUERO BLANCO, I. (2017). La ficción sonora y la realización en directo: el reto de RNE. Área Abierta. Revista de comunicación audiovisual y publicitaria, 17(1), 117-146. Recuperado el 1 de febrero de 2019, desde: https://revistas.ucm.es/index.php/ARAB/article/view/54404

ARNHEIM, R. (1980). Estética radiofónica. Barcelona: Gustavo Gili.

BALSEBRE, A. (2007). El lenguaje radiofónico. Madrid: Cátedra.

BAlSEBRE, A. (2002). Historia de la radio en España. Vol. II (1939-1985). Madrid: Cátedra.

BAREA, P. (1994). La estirpe de Sautier. La época dorada de la radionovela en España (1924-1964). Madrid: El País Aguilar.

BAREA, P. (2000). Teatro de los sonidos, sonidos del teatro: teatro-radio-teatro, ida y vuelta. Bilbao: Universidad del País Vasco. Servicio Editorial. Euskal Herriko Unibertsitatea. Argitarapen Zerbitzua.

CAMACHO, L. (1999). La imagen radiofónica. McGraw-Hill: México.

CASETTI, F. y DI CHIO, F. (1999): Análisis de la televisión. Instrumentos, métodos y prácticas de investigación. Barcelona: Paidós.

GARCÍA JIMÉNEZ, J. (1996). Narrativa audiovisual. Madrid: Cátedra.

GARCÍA LANDA, J. A. (1998). Acción, relato, discurso. Estructura de la ficción narrativa. Salamanca: Ediciones Universidad de Salamanca.

GARCÍA PEINADO, M. A. (1998). Hacia una teoría general de la novela. Madrid: Arco Libros.

GARCÍA, Ma . C. y BERGANZA Mª R. (2005). El método científico aplicado a la investigación en Comunicación Mediática. En Ma . R. BERGANZA y J. A. RUIZ SAN ROMÁN (Coord.): Investigar en Comunicación: guía práctica de métodos y técnicas de investigación social en Comunicación (pp. 19-42). Madrid: McGraw-Hill.

GUARINOS, V. (2009). Narrativa radiofónica. Madrid: Síntesis.

GENETTE, G. (1989). Figuras III. Barcelona: Lumen.

HeRnández SAMPIERI, R.; FERnández COllado, C. y Baptista Lucio, P. (2010). Metodología de investigación. México: Mc Graw-Hill.

HuRTADO, C. (2008). Montando Siritinga. Enlaces: revista del CES Felipe II, 9. Recuperado el 15 de febrero, 2019, desde: 
index•comunicación| número monográfico 9(2), 2019 Radioteatro

http://www.cesfelipesegundo.com/revista/articulos2008b/ARTICULO CAR LOS_HURTADO_corregido.pdf

IGARTUA, J. J. (2006). Métodos cuantitativos de investigación en comunicación. Barcelona: Bosch Comunicación.

KAPLÚN, M. (1978). Producción de programas de radio. Quito: Ciespal.

MARTínEZ-COSTA, M. P. (1998). Tipología y funciones del narrador en los relatos radiofónicos. Comunicación y Cultura, 5/6, 97-104. Recuperado el 10 de febrero, 2019, desde:

file://C:/Users/usuario/Downloads/Dialnet-

TipologiaYFuncionesDelNarradorEnLosRelatosRadiofon2901327\%20(1).pdf

MAZA, M. y CERVANTES, C. (2000). Guión para medios audiovisuales: cine, radio y televisión. México: Pearson Educación.

ORTIZ SOBRINO, M. A. y VOLPINI, F. (2017). Realización, lenguaje y elecciones narrativas de radioteatro: tres aproximaciones a la creación de espacios sonoros en el tiempo. Área Abierta. Revista de comunicación audiovisual y publicitaria, 17(1), 13-36. Recuperado el 17 de febrero, 2019, desde: https://revistas.ucm.es/index.php/ARAB/article/view/53496

Radio Barcelona (1925-1958). Colección de guiones de la programación diaria de Radio Barcelona (1925-1958). [Manuscrito]. Barcelona: Universidad Autónoma de Barcelona. Biblioteca de Comunicación y Hemeroteca General.

Radio Barcelona (1950-1966). Colección de guiones de Taxi Key [Manuscrito]. Barcelona: Archivo de Radio Barcelona. Cadena SER.

RODERO, E. (2005). Producción Radiofónica. Madrid: Cátedra.

RODERO, E. y XOENGAS, X. (2010). Elaboración del relato en la ficción radiofónica. En E. RODERO y X. SOENGAS: Ficción radiofónica: cómo contar una historia en la radio (pp. 101-149). Madrid: Instituto RTVE.

Para citar este trabajo: Arias-García, E. (2019). La figura del narrador en la ficción radiofónica seriada: el caso de Taxi Key. index.comunicación, 9(2), 101-134. 